\title{
A magia do feitiço: apropriações africanas no Brasil
} Colônia ${ }^{1}$

\author{
"The witchcraft magic": African appropriations in \\ Brazil Colony
}

Glícia CALDAS

\begin{abstract}
RESUMO
O presente estudo visa examinar as concepções de entendimento da religiosidade africana nas colônias atlânticas portuguesas. $\mathrm{O}$ objeto central é a implicação da transposição do discurso europeu sobre "feitiçaria" para as práticas religiosas africanas. Visitar ritos e simbolismos religiosos dos povos da diáspora africana é imprescindível para o entendimento de "agregações", "apropriações" e "recriações" de representações culturais dos grupos de africanos escravizados que foram transmigrados para o Brasil. Examinaremos as colônias portuguesas africanas da região dos Bacongos, nome pelo qual a Antropologia e a História têm identificado os povos habitantes das regiões dos atuais Congo e Angola. Alguns estudos importantes perceberam bem a relação entre a feitiçaria e as tensões sociais. É necessário compreendermos o significado da "feitiçaria" para uma grande parte da África, em comparação com a perspectiva ocidental. O africano escravizado buscou e utilizou diversas formas de resistências, tentando minimizar a adversidade das relações escravas. As práticas da magia são inseridas em uma das formas de resistência escrava contra o sistema escravista, como instrumento legitimador da repressão e violência.
\end{abstract}

Palavras-chave: África, magia, religiosidade, resistência escrava.

\section{ABSTRACT}

The present study analyzes the conceptions of agreement of the African religiosity in the Portuguese Atlantic colonies. The central object is the implication of the transposition of the European speech about "witchcraft" for the Africans religious practices. To visit ceremonies and

\footnotetext{
${ }^{1}$ Este artigo foi apresentado no II Simpósio Internacional sobre Religiões, Religiosidade e Culturas, Dourados/MS- Brasil, 2006.
} 
religious symbolisms of the African Diaspora peoples is essential for theagreement of "aggregations", "appropriations" and "new creations" of cultural representations of the groups of enslaved Africans who had been transmigrated to Brazil. We will examine the African Portuguese colonies of the region of the Bacongos, name that the Anthropology and History have identified to the peoples inhabitants of the Congo and Angola current regions. Some important studies had perceived the good relation between witchcraft and social tensions. It is necessary to understand the meaning of "witchcraft" for a great part of Africa, in comparison to the occidental perspective. The enslaved African searched and used diverse resistance forms, trying to minimize the enslaved relations adversity. The witchcraft practices are inserted in one of the forms of enslaved resistance against the slavish system, as legislator instrument of the repression and violence.

Index Terms: Africa, enslaved resistance, magic, religiosity.

\section{Introdução}

Um negro angola forro Domingos Umbata ${ }^{2}$, em Salvador, no ano de 1646, foi denunciado e preso pelo Santo Ofício por ajudar duas "pretas" a melhorar seus relacionamentos com suas "donas". As senhoras eram perversas e imputavam às "pretas" muitos castigos. Para proteger as escravas da fúria de suas senhoras, Domingos fazia com que se banhassem em uma bacia de água que continha folhas esmagadas, um guizo e um dente de jaguar, que deveria ter trazido do continente africano ou comprado de algum outro africano recém chegado. Presumivelmente, o banho as protegia das agruras do cativeiro, do poder do "feiticeiro branco" que poderia usar de suas forças para trazer algum infortúnio às "pretas". Os africanos escravizados utilizavam ritos e ícones da religião de matriz africana como forma de se proteger nas relações escravas, muitas vezes, como forma preventiva aos ataques dos seus senhores.

\footnotetext{
${ }^{2}$ Arquivo Nacional da Torre do Tombo, Lisboa/Portugal ( ANTT), Inquisição de Lisboa, Cadernos do Promotor, n. 29, livro 228, p. 4-4v.
} 
Os africanos escravizados e forros no Brasil Colônia, numa sociedade senhorial, elitizada, em uma escala hierarquizada, estavam na base da pirâmide da hierarquia e os senhores "brancos" no ápice. Impostos à degradação física, moral e psicológica pelo sistema escravista, sua difícil condição de sobrevivência era de, algum modo, compensada com práticas mágicas; freqüentemente, aqueles que eram especialistas em manipulações com forças sobrenaturais, eram chamados de "feiticeiros". Detentores de saberes "mágicos", a fama pública fazia-os requisitados também pelos senhores, o que geralmente elevava seu status junto à sua própria comunidade e possibilitava, através das práticas mágico-religiosas, a obtenção de ganhos materiais, não só em dinheiro, mas também em gêneros. Para os senhores, era um grande inconveniente ter seus escravos identificados como feiticeiros pela Inquisição, uma vez que estes, quando presos, dificilmente retornavam aos seus ofícios. "Negros feiticeiros" também se armaram com suas "bruxarias", para se defenderem das agruras do cativeiro, em tentativas variadas de aplacar a ira senhorial, escaparem de castigos e maus-tratos; dessa forma, resistindo cotidianamente à sua condição.

No Brasil, os africanos escravizados urdiram toda sorte de magia para se livrarem da ira de seus senhores. A resistência ao sistema escravista no mundo colonial se apresentou sob diversas formas, desde formas explícitas - como fugas individuais e coletivas, revoltas e formação de quilombos - até as mais sutis, vinculadas ao cotidiano e vivenciadas no interior do próprio sistema, como roubos, suicídios, abortos, assassinatos e boicotes à produção senhorial ${ }^{3}$. As práticas de magia inseriram-se nessa segunda categoria, sendo consideradas necessárias à formação social escravista colonial, uma vez que eram, ao mesmo tempo, alternativas de luta

\footnotetext{
${ }^{3}$ REIS, João J.; SILVA, Eduardo (1989). Negociação e conflito: a resistência negra no Brasil escravista.
} São Paulo: Companhia das Letras. 
contra o sistema, "muitas vezes a única possível"4 , assim como instrumento legitimador da repressão e violência.

Alguns estudos importantes perceberam bem a relação entre a feitiçaria e tensões sociais. Entre eles, o trabalho de Evans-Pritchard ${ }^{5}$, sobre as bruxarias utilizadas pelos Azande, do sul do Sudão e nordeste do Congo, publicado em 1937. O autor mostrou o papel da feitiçaria como um mecanismo de escape às tensões e aos medos, encarnado na figura do bruxo. Cerca de trinta anos depois de seus estudos, esta análise foi objeto de reflexão acerca da feitiçaria européia. As mazelas trazidas por um século XIV difícil, com pestes, fome, crise econômica, desesperança, pessimismo, herança abraçada pelo alvorecer da Época Moderna e acrescida, ainda, de conflitos religiosos, fizeram aumentar cada vez mais as pressões sociais. Assim, as desgraças que assolavam os indivíduos eram encarnadas na figura da bruxa, responsabilizada por muitas destas intempéries. Segundo Jean Delumeau (1996, p.376):

[...] na estrutura de uma sociedade que ainda permanecia amplamente no estágio mágico, a bruxa era necessária, portanto, como bode expiatório, sendo aliás verdade que certos indivíduos realmente procuraram desempenhar esse papel nefasto de enfeitiçador.

Para Marc Augé (1982, p.219), as bruxas tentam resolver as angústias existenciais das suas épocas e de suas culturas, desempenhando uma função social reconhecida:

Sublinha que as descrições de "bruxaria" africana que pôde fazer "ao vivo" (através das confissões dos acusados, o rumor público ou os especialistas locais da cura e da contra feitiçaria) evocam de maneira bastante notável aquelas que

\footnotetext{
${ }^{4}$ MELlo E SOUZA, Laura de (1986). O Diabo e a terra de Santa Cruz: feitiçaria e religiosidade popular no Brasil. São Paulo: Companhia das Letras, p. 205. No Brasil essa crença no poder redentor e purificador da violência física encontrou poderoso aliado na necessidade escravista do castigo exemplar. Escravos podiam ser legitimamente castigados também porque eram feiticeiros. Enxergá-los como feiticeiros, por sua vez, foi uma das manifestações da paranóia das camadas senhorial na colônia.

5 EVANS-PRITCHARD, E. (1978a). Bruxaria, Oráculos e Magia entre os Azande. Rio de Janeiro: Zahar.
} 
puderam recolher no seu tempo os inquisidores e os juízes; os temas do desdobramento, a metamorfose e a ambigüidade da relação feiticeiro/contra feiticeiro, nomeadamente, apresentam sobre os dois continentes, em uma e a outra história, numerosas analogias.

É necessário compreendermos o significado da categoria "feitiçaria" para a África Banto, responsável pela grande maioria dos africanos escravizados, transladados para o Brasil, em comparação com a perspectiva ocidental, traçando-se um arcabouço da religiosidade da população negra no Brasil Colônia, através do universo da "magia do feitiço", utilizado para uma gama variável de situações: problemas amorosos, dificuldades financeiras, curas de doenças, minimização das dificuldades das relações entre senhores e escravos. Outras, como um contra feitiço, para contra atacar, como um "remédio", para as mazelas provocadas por feitiços, sejam do corpo ou do espírito. Através das práticas mágico-religiosas o africano escravizado buscou e utilizou diversas formas de resistências, tentando minimizar a adversidade das relações escravas.

O presente estudo visa examinar as concepções de entendimento da religiosidade africana nas colônias atlânticas portuguesas. O objeto central é a implicação da transposição do discurso europeu de "feitiçaria" para as práticas mágico-religiosas de matriz africana. Com os africanos escravizados e as mercadorias africanas, oriundos da região dos Bacongos, vinham as representações culturais de sua cosmogonia, maneiras de lidar com as coisas do mundo real e do espiritual. Bacongo é o nome pelo qual a Antropologia e a História têm identificado os povos habitantes de regiões dos atuais Congo e Angola, constituintes do tronco lingüistico Bantu. Algumas dessas formas podem ser identificadas nas representações culturais recriadas por africanos de origem Banto e por seus descendentes, pelas várias maneiras que os Bacongos reinterpretavam símbolos e rituais estrangeiros, em termos básicos de sua cultura de origem. 


\section{Cosmogonia africana}

\section{Feitiço e contra-feitiço}

A cosmogonia africana é harmônica, o universo é coeso, e tudo que o desequilibra é visto como sobrenatural, sortilégio mágico, produto de feitiçaria. O sagrado permeia, de tal modo, todos os setores da vida africana, que torna impossível realizar uma distinção formal entre o sagrado e o secular, entre o espiritual e o material nas atividades do cotidiano. Uma força, um poder ou uma energia permeia tudo. Como diz Tempels ${ }^{6}$, o valor supremo é a vida, a força, viver forte ou força vital. Essa força não é exclusivamente física ou corporal e sim uma força do ser total, sendo que sua expressão inclui os progressos de ordem material e o prestígio social. Felicidade é possuir muita força, e infelicidade é estar privado dela. Toda doença, todo flagelo, todo fracasso e toda adversidade são expressões da ausência de força. Os símbolos e rituais dotam a comunidade de uma força e proteção especiais frente à adversidade da vida diária; seu objetivo principal é preservar a "vida boa",

A prática do mal era apenas um componente do que deve ser entendido como um pacote de forças religiosas ocultas. Em muitas sociedade africanas, não havia nenhum diferencial que distinguisse os bons rituais dos rituais malévolos. Os rituais e simbolismos empregados eram os mesmos para o bem e o mal; a diferença estava na finalidade ao qual se

\footnotetext{
${ }^{6}$ TEMPELS, R. P. P. La philosophie bantoue. Paris: Colléction Présence Africaine, 1949. Também para o ocidente, existe essa mesma concepção, nas camadas populares até o fim do século XIX. Banto, palavra que significa "homens ou povo", (no sentido coletivo ou plural, sem a escrita da letra "s"), Bantu é o singular, definições aceitas para a grande maioria desses idiomas. $\mathrm{O}$ tronco lingüístico Bantu é composto por vários grupos étnicos onde na diversidade das línguas entre os povos muitos dos vocábulos raízes indicavam os conceitos básicos da vida cotidiana. Um estudo mais detalhado ver SLENES, Robert, Malungu, ngoma vem! África coberta e descoberta no Brasil. Revista da USP, São Paulo, n ${ }^{\circ}$ 2, pp.12-67, 1991-1992, p. 50.

${ }^{7}$ Ver CRAMER, Willy; VANSINA, Jan; FOXES, Renée (1976). "Religious movements in central Africa: a theoretical study". In: Comparative studies in society and History, (18), p. 458-475. "Vida Boa" para os banto era representada pela presença da harmonia e equilíbrio, através de uma força espiritual mágica (p. 468).
} 
destinavam $^{8}$. As forças poderiam ser usadas para uma variedade de atuações positivas, adivinhações, curas, fertilidade, auxílio com o gado, colheitas, sempre visando restabelecer a harmonia, seja no plano individualizado ou coletivo. Por outro lado, essas mesmas forças poderiam ser usadas nas práticas de danos individuais ou coletivos. Para essas sociedades, se um adivinho ou curandeiro tinha o poder de ver espíritos maus e expulsá-los com seus poderes, então, certamente, estava habilitado a controlar formas similares do mal, para os próprios propósitos nefastos dele. Esta circulariedade entre o mágico, a divindade e a reparação demonstra a extraordinária natureza ambígua do discurso religioso nas sociedades africanas, estando presente a mesma dicotomia no catolicismo.

$\mathrm{Na}$ África Central, os entendimentos sobre malevolência religiosa estavam ligados a um infortúnio temporário, especialmente causado pela força humana oculta, através do binômio ventura/desventura. Aqueles que usavam suas forças mágicas para causar danos a outros ou para benefícios próprios, ao invés do melhoramento de sua comunidade, eram considerados malévolos. Um dos aspectos de malevolência era um crescimento social e/ou econômico desigual entre o mágico e todos ou demais da comunidade. Assim, dois dos sistemas clássicos da malevolência religiosa eram o injusto sofrimento das vítimas e a rápida, inexplicável, prosperidade social e econômica por parte dos atormentadores espirituais. $\mathrm{Na}$ perspectiva africana, escravidão e exploração econômica dos europeus preencheram esses critérios, mas o impacto dessas fortes e desconhecidas novas formas de malevolência transformaram radicalmente o significado religioso na África e na diáspora.

Antes do contato com os europeus, os africanos viam a malevolência religiosa através de um prisma micropolítico que permitia um antídoto

${ }^{8}$ Cf. Evans-Pritchard, op. cit., p.462. O autor analisa a feitiçaria como um sistema cognitivo capaz de explicar o infortúnio. 
religioso familiar. Bondade e maldade eram parte da mesma continuidade cosmológica, e ambos poderiam ser controlados com práticas e rituais religiosos familiares. Os europeus introduziram uma nova forma de malevolência social e econômica, o comércio de escravos do Atlântico, que transformou esse equilíbrio cosmológico. Guerras, doenças, migração forçada e outros infortúnios instigados pelo desejo europeu do trabalho escravo, tudo era entendido como parte dos poderes dos "feiticeiros brancos", os europeus.

Segundo Sweet $^{9}$ muitas sociedades da costa central africana acreditavam que os europeus levavam os africanos escravizados para "comê-los", e aproveitar suas "partes", transformando-os em produtos que seriam retornados ao comércio na África. Acreditavam que o óleo comestível era obtido da gordura dos corpos africanos, os vinhos vermelhos eram o sangue, os queijos europeus eram os cérebros de suas vítimas. A pólvora era as cinzas dos ossos dos africanos escravizados que eram queimados pelos seus algozes. Este entendimento era embasado na cosmogonia das sociedades da costa central africana, em que Kalunga ${ }^{10}$, era a travessia do mundo real para o mundo espiritual; assim, transpor a Kalunga, em navios negreiros, representava uma morte prematura, nas mãos dos "feiticeiros brancos" (os europeus), que se alimentavam dos corpos negros na terra dos mortos, as Américas. Para os bacongos, a cor branca simbolizava a morte, os homens eram pretos, os espíritos, brancos. Como resultado desta crença, do tráfico de africanos escravizados e da associação do oceano com a Kalunga, foi fácil para os bacongos identificar a terra dos brancos com a dos mortos. Com esse entendimento sobre a malevolência e prosperidade dos europeus, demonstra quão profundamente o mercado

${ }^{9}$ SWEET, James H. (2003). Recreating Africa: culture, Kinship, and religion in African-Portuguese World, 1441-1770. London: The University of North Caroline Press, 2003, p. 162.

${ }^{10}$ Para os banto, Kalunga significava a travessia do mundo dos vivos para o mundo dos mortos, o oceano ficou conhecido pela mesma palavra, pois atravessá-lo significava o ingresso no outro mundo, o dos 
escravo impactou o discurso africano. Para eles, os europeus usavam de feitiçaria, forças ocultas, para escravizar e comercializar os corpos negros para o próprio enriquecimento.

Se o comércio escravo e a exploração econômica foram o impulso transformador de certas formas religiosas "malévolas" em "feitiçaria" na África, então, verdadeiramente, a escravidão pelos europeus deve ser entendida como a mais mortal forma de feitiçaria dos "feiticeiros brancos". Necessitando de um poderoso contra-ataque mágico-religioso africano, objetivando libertá-los da maldição, esta postura defensiva, por parte dos africanos escravizados, direcionou-os para frente do discurso de feitiçaria do mundo ocidental. Por outro lado, os portugueses já conviviam com um discurso sobre feitiçaria, antes de entrarem em contato com as sociedades africanas. O que eles fizeram foi transferir para o contexto africano a história estabelecida sobre feitiçaria e feiticismo. Por falta de uma literatura africana sobre a feitiçaria, a igreja portuguesa aderiu ao amplo contorno da construção européia da feitiçaria. Era amplamente entendido que Deus usava feitiços, e o demônio, para punir pecadores e testar a fé humana. O uso da força diabólica para contra-atacar a própria força do diabo foi proibida pela igreja, porque isto, necessariamente, significava invocar o demônio. Apenas a prece e a fé em Deus poderiam contra-atacar o poder diabólico de maneira segura e cristã.

Antes do século XVII, os teólogos inquisitoriais portugueses começaram a comentar mais largamente sobre a origem da feitiçaria. $\mathrm{Na}$ visão de filósofos portugueses sobre feitiçaria, rituais, orações e símbolos usados para contra-atacar o mal, eram todos evidências de pacto com o diabo. Mesmo os rituais que envolviam preces cristãs e uso de objetos sagrados eram suspeitos, porque eles, na maioria das vezes, eram utilizados

espíritos. Ver SLENES, op. cit., 1991-1992. Nas páginas 53 e 54 o autor analisa a etimologia e a simbologia da palavra Kalunga. 
pelas pessoas "profanas" que eram contrárias à santidade das palavras ou aos objetos que eram utilizados. Para os portugueses, essas pessoas eram todas consideradas como ignorantes, exóticas, primitivas. Já durante o século XVII, o entendimento português sobre feitiçaria foi fundindo-se com o surgimento do discurso de classe social, uma classe literata, educada e "civilizada", tentando distanciar-se das massas populares, que eram declaradas como mergulhadas no mundo vulgar da superstição e da magia. O clero, os juízes, os médicos e a maioria da elite acreditavam na força do demônio manipulada através dos "feiticeiros". Eles não acreditavam que a feitiçaria fosse uma ameaça real para a ordem e a razão cristã. A maioria dos feiticeiros portugueses atuavam sozinhos e não em grupos. $\mathrm{O}$ alarme que contagiou outros países europeus não foi estendido a Portugal ${ }^{11}$. Acreditavam que, pelo uso dos recursos de Deus - batismo, confissão, comunhão, orações, e exorcismo —, feiticeiros individuais poderiam ser combatidos. Essas crenças foram estendidas ao Brasil, desde a época da colônia, quando os feiticeiros portugueses encontravam práticas religiosas africanas. A diferença entre o Brasil e Portugal era que os "feiticeiros" africanos estavam presentes em grande número no Brasil, eram capazes de usar sua força espiritual contra seus senhores, inclusive fisicamente, e ameaçando a fé católica. Todas as práticas religiosas africanas eram suspeitas de serem rituais demoníacos.

Sweet ${ }^{12}$ nos alerta que, na maioria das sociedades da África Central, a escravidão era compreendida como o resultado da maldade religiosa de Portugal, contrária aos mais poderosos antídotos religiosos africanos, que eram reconhecidos e temidos pelos portugueses. Na tentativa de extinguirem ou minimizarem as tormentas da escravidão, os maus tratos, o rompimento de linhagens, a má nutrição, a vestimenta, as doenças, a separação de

11 PAIVA, José Pedro (1997). Bruxaria e superstição num país sem “caça às bruxas”: 1600/1774. Lisboa. Notícias Editorial, p.104.

${ }^{12}$ Sweet, 2003, op. cit., p.163. 
parentesco e outros, os africanos escravizados e libertos adaptaram práticas mágico-religiosas para contra-atacar o que eles acreditavam ser "feiticeiros brancos", causadores de sortilégios mágicos, do infortúnio.

Outras formas mais poderosas eram dirigidas diretamente ao senhor ou à sua família. Lembrando que, na concepção africana, os europeus eram "feiticeiros brancos", os mais poderosos antídotos religiosos africanos pretendiam mutilar ou matar os brancos e as suas famílias. Os senhores eram conscientes da vingança dos africanos escravizados ${ }^{13}$. Não só os africanos escravizados utilizavam os feitiços como formas de resistências individuais; os forros, também, usaram suas forças religiosas para expressarem mágoas contra os brancos. A recusa de alguns brancos em acreditar nas formas africanas de feitiçaria variava em função de diversos fatores, principalmente a confusão entre veneno e feitiço, pela crença popular. Muitos ingredientes, usados nas misturas da "feitiçaria" pelos africanos escravizados ou forros, eram peçonha, veneno, misturas de raízes, ervas. Os ritos e simbolismos religiosos africanos eram considerados demoníacos. Os envenenamentos eram incluídos dentro das práticas da magia, sendo, apenas, um outro lado dos feitiços africanos, pela transposição do discurso europeu da "feitiçaria" para as "práticas mágicas africanas". Pelas mesmas razões de dominação e com formas bem parecidas, um "criado", na Europa, que pretendesse se vingar de seu senhor usando veneno, seriam atribuídos a esse ingrediente poderes mágicos malévolos.

$\mathrm{Na}$ compreensão africana, venenos portugueses eram substâncias comuns carregadas de simbolismos sagrados, ou seja, acrescidos da "força mágica”, para agir contra outras formas de feitiçaria ou malevolência.

\footnotetext{
13 Outros exemplos sobre "feitiços" usados por africanos escravizados contra seus senhores, em formas "mais brandas" ou "mais poderosas", utilizados, na maioria das vezes, como forma de prevenção, ver Sweet, 2003, op. cit., capítulo 8, "Witchraft, ritual, and resistance in the African-Portuguese diaspora".
} 
Segundo Sweet ${ }^{14}$, as tentativas dos africanos escravizados de exterminarem com os seus senhores, através de venenos, eram, provavelmente, melhor entendidas, como tentativas de erradicar os "feiticeiros brancos". As respostas africanas aos feitiços dos senhores eram um contra-feitiço mais poderoso. Os mesmos ingredientes usados nas fórmulas para curar doenças eram, também, utilizados para provocar males, sempre carregados de ritos e ícones sagrados. Quase sempre, o resultado era atribuído a uma deidade e nunca a uma substância natural, legitimando o "poder" e a "força" no sagrado. $\mathrm{O}$ veneno transformado em feitiço era uma das formas de controle africano, no discurso entre sagrado e profano em Portugal e no Brasil, potencializando a "magia africana", além de ser uma das importantes formas de resistência africana na diáspora. Todo ato de feitiço, entre os próprios africanos escravizados, usando forças sagradas africanas, era sempre mais do que um ataque individual, era, também, um ataque contra um "bem" material, atingindo o estado econômico e social de seu senhor, tornando-se um ato de resistência individual contra a dominação escravista. No Brasil, a utilização dos ritos e simbolismos sagrados africanos persistiu através do entendimento de sua transformação em feitiçaria; com um número elevado de africanos escravizados, foi comum o temor dos seus donos pela destruição de suas propriedades humanas, através do uso de práticas religiosas, mais complexas e mais divulgadas aqui do que na África.

\section{O equilíbrio harmônico e o papel do adivinho}

Entre os vários papéis dos agentes religiosos africanos estava a figura do adivinho, de real importância para o equilíbrio harmônico da comunidade africana, e soube ser devidamente apropriado pelos senhores de escravos no Novo Mundo. Realizavam uma variedade de atividades ritualísticas para invocar os espíritos ancestrais, fazendo a intercomunicação entre o mundo dos vivos e dos além-túmulos. Medianeiro entre os dois

\footnotetext{
${ }^{14}$ Sweet, 2003, op. cit., p.169.
} 
espaços, sagrado e profano, poderia ele predizer acontecimentos passados e futuros, descobrir culpados por ilícitos, causas de doenças, feitiços, e atuar na pacificação das sociedades africanas, referente ao seu equilíbrio e harmonia interna.

Na intercomunicação entre os dois mundos, a revelação deveria ser legitimada pela sociedade, ou seja, o adivinho fazia as revelações, mas a interpretação dela era deixada para a visão da comunidade; a atuação do adivinho era vista, geralmente, como "um serviço social", como ponto principal para uma sociedade equilibrada e pacífica. Com a transformação interna na África, a ruptura social provocada pelo sistema escravista reelaborou as funções do adivinho, para melhor adaptação da "nova identidade" escrava, buscando explicações no mundo espiritual para escravidão. Nas comunidades escravas nascidas na diáspora, os africanos utilizavam os adivinhos, na tentativa de "criar" os mesmos modelos de equilíbrio comunitário que os ajudavam em sua terra de origem.

Reconhecendo a larga aceitação da adivinhação nas comunidades escravas, os senhores usavam os africanos escravizados, especialistas da adivinhação, para adivinhar quem havia cometido algum ilícito contra eles, seja roubo, uso da feitiçaria ou fuga. Porque os rituais de adivinhação ressoavam com a maioria das tradições culturais dos escravos, as adivinhações eram quase sempre aceitas como válidas, mesmo quando os indicados do mal eram os próprios africanos. Isto reforçou os mecanismos religioso-judicial da instituição escravista, auxiliando o senhor a determinar a culpabilidade dos "rebeldes", contra a escravidão. Mas era, também, uma indicação da classe senhorial de apropriação de uma instituição africana de controle social $^{15}$.

\footnotetext{
${ }^{15}$ Sweet, 2004, op. cit. p. 141. Outro exemplo de apropriação de instituição africana pelos portugueses, é o mecanismo de mocano, citado por Roquinaldo Ferreira, "Transforming Atlantic slaving: trade, warfare and territoriae control in Angola, 1650-l800". PHD dissertion, Ucla, 2003. Este mecanismo era utilizado por
} 
A adivinhação "adaptou-se" às novas mudanças nas relações sociais, na colônia portuguesa na América, "construindo" um arcabouço entre os interesses dos senhores e da aceitação pela comunidade africana. $\mathrm{Na}$ Bahia, em 1685, André Gomes de Medina ${ }^{16}$ havia perdido 15 escravos vítimas de "feitiçaria"; a acusação recai sobre um negro forro Simão Congo, exescravo de André. Em busca de indícios que servissem para comprovar a acusação, a única prova foi a descoberta de algumas panelas com ervas, unhas, dentes e pêlos de vários animais, na casa do "suspeito". Impossível saber quais eram as especificidades dos ingredientes encontrados na dita panela. O Sr. André chamou uma adivinha, escrava negra, Gracia Conga, de outra fazenda, para desvendar o "mistério". Na propriedade do senhor, a adivinha preparou certos rituais, na presença de todos. Ela ateou fogo em alguns gravetos, sobre eles um grande pote com água para ferver, com algumas pedras dentro. Todos deveriam retirar uma das pedras do pote fervendo, somente o culpado sairia queimado. Os presentes fizeram uma roda em volta do pote fervendo, Gracia dançou em torno dele, no sentido anti-horário, a dança dos adivinhos - "dançar avure", cantando e dizendo palavras, provavelmente, em seu idioma de origem. Cada um, por sua vez, foi colocando uma das mãos dentro do pote com água fervendo, e retirando uma das pedras. Nos escravos, forros e brancos, apenas pequenas e leves queimaduras aconteceram. O forro Simão Congo, ao retirar sua mão e braço, estava com várias queimaduras graves. O ritual de adivinhação realizado pela escrava Gracia Conga confirmou a suspeita já existente, de que o ex-escravo seria o culpado ${ }^{17}$. Ele se defendeu, alegando que na panela

africanos livres nas sociedades autóctones africanas na região de Angola, atual. Quando eram presos injustamente e vendidos como escravos, interpõem um pedido a autoridade local, alegando suas razões e solicitando sua intervenção. É incorporado pelos Governadores Gerais de Angola, no século XVII.

${ }^{16}$ Arquivo Nacional da Torre do Tombo, Lisboa/Portugal, Inquisição de Lisboa, processo $n^{\circ} 8464$.

${ }^{17}$ CAVAZZI, Padre Giovanni Antonio (1965). Descrição Histórica dos três reinos do Congo, Matamba e Angola. Lisboa: Notícias, p. 109. Os rituais praticados pela africana escravizada era largamente utilizados na África Central, com alterações entre o continente africano e o reproduzido no Brasil. O autor descreve quando um feiticeiro coloca um pote com água para ferver, dentro uma pedra. Os acusados deverão retirar a pedra com suas mãos, aquele que não sair com queimaduras será aclamado inocente, dando-se o caso por encerrado. Quem se queimasse seria julgado culpado. O ritual é realizado na presença da comunidade, mas 
encontrada eram "preparados" medicinais contra mordida de cobra. Alegou, também, que a acusação dos escravos, dirigida a ele, era por ciúme, pela condição de ser livre. A liberdade foi-lhe concebida pela filha de André Gomes de Medina, tornando-se um lavrador de madeira. A adivinhação, simplesmente, confirmou a culpa de quem já era considerado culpado, atuando como um mecanismo religioso-judicial. O resultado foi satisfatório para ambos os lados envolvidos. O culpado era alguém de fora da comunidade escrava, reestabelecendo o equilíbrio, e reforçando o ritual como uma solução favorável para todos. A liberdade e a ascensão do negro forro Simão eram vistos como resultados de algumas manipulações de forças sobrenaturais, até "feitiçarias". Para o entendimento africano de malevolência religiosa, aqueles que usavam "forças mágicas" para benefício próprio, ao invés do melhoramento de sua comunidade, eram considerados malévolos. A ascensão rápida, de um escravo para um liberto economicamente auto-suficiente não era explicável por forças naturais, humanas e, sim, através de manipulações de forças espirituais malévolas.

A apropriação, pelos portugueses, da instituição de adivinhação africana pode ser compreendida como uma importante concessão de força judicial, implicando a diminuição das formas das estruturas judiciais dos senhores. Sendo a instituição jurídico-legal da colônia um tanto quanto precária, principalmente em áreas rurais, uma parte considerável de senhores buscou legitimar esta "força" religioso-judicial, que na África central era denominada de provação de jaji. Este mecanismo fez sua travessia pelo Atlântico em uma forma aproximada à sua estrutura original, adaptando-se às novas condições do sistema escravista. Os africanos escravizados atribuíam a outros africanos a culpa; nessas cerimônias de julgamento, os rituais poderiam ser vistos, simplesmente, como formas de

para sua legitimação deve ser confirmado pelos oráculos, o que não acontecia no Brasil. Existem outros relatos com rituais iguais na África, conhecido como a provação de jaji. Sobre os ritos dos adivinhos ver 
justiça africana, isentando os senhores de qualquer tipo de perseguição aos seus "bens".

Um outro ponto a ser observado nesse mecanismo era, em alguns raros casos, os brancos aceitarem as culpas dos ilícitos de seus próprios parentes e amigos. Antonio da Guiné ${ }^{18}$, escravo na Bahia, procurado para adivinhar quem havia roubado dinheiro e uma cruz de prata do seu senhor, utilizou uma bacia com água para as práticas da adivinhação. Não fica esclarecida nos documentos, a real origem africana de Antonio. Presumindo que seja da África central, a crença de que a linha divisória entre os dois mundos, o material e o dos espíritos, era a de um espelho d'água, um especialista "mágico-religioso" poderia fazer contatos com os mortos, os antepassados, e obter orientações, respostas para as dificuldades de vida real. Antonio, olhando a água, proferindo orações, presumivelmente, em algum idioma africano, obteve a resposta esperada: o roubo fora efetuado pelo filho mais novo do seu "dono", revelando, também, onde estava escondido, dentro de uma caixa, em baixo de uma das camas da casa. Achada a caixa, dentro estavam o dinheiro e a cruz, no lugar indicado. O resultado foi aceito pelo seu senhor, mas, infelizmente, os documentos silenciaram sobre quais foram as atitudes da punição pelo roubo. Porém, podemos atrever-nos a supor que o senhor não imaginaria que o responsável fosse um de seus filhos. A força da estrutura tornou-se completamente confusa, transformando a adivinhação em outra forma de resistência escrava.

Várias vezes os senhores procuravam os adivinhadores africanos para desempenharem suas atividades para eles. Os africanos eram capazes de transformar a força religiosa em resistência à sua escravização,

Evans-Pritchard, op. cit., Bruxaria, Oráculos e Magia entre os Azande, 1978 (a), cap. V, Os adivinhos, p.107-132. 
conseguindo prestígio, não somente junto à sua comunidade, mas também entre outras pessoas que acreditavam em suas práticas mágico-religiosas. Consultar adivinhos africanos foi uma "aceitação" da cosmologia da África, resultando em uma das rachaduras, no sistema colonial português.

\section{Referências bibliográficas}

AUGÉ, Marc (1982). Le Génie du paganisme. Paris: Gallimard.

CAVAZZI, Padre Giovanni Antonio (1965). Descrição Histórica dos três reinos do Congo, Matamba e Angola. Lisboa: Notícias.

CRAMER, Willy; VANSINA, Jan; FOXES, Renée (1976). "Religious movements in central Africa: a theoretical study". In: Comparative studies in society and History, (18), p. 458-475.

DELUMEAU, Jean (1989). O Medo do Ocidente, 1300-1800: uma cidade sitiada. São Paulo: Companhia das Letras.

EVANS-PRITCHARD, E. (1978a). Bruxaria, Oráculos e Magia entre os Azande. Rio de Janeiro: Zahar.

Campus.

(1978b). Antropologia Social da Religião. Rio de Janeiro;

FERREIRA, Roquinaldo (2003). Transforming Atlantic slaving: trade warfare and territoriae control in Angola, 1650-1800. PHD-Dissertion, UCLA.

MELlO E SOUZA, Laura de (1986). O Diabo e a terra de Santa Cruz: feitiçaria e religiosidade popular no Brasil. São Paulo: Companhia das Letras.

MINTZ, Sidney W.; PRICE, Richard (2003). O Nascimento da Cultura Afro-americana: uma perspectiva antropológica. Rio de Janeiro: Pallas; Universidade Candido Mendes.

\footnotetext{
${ }^{18}$ Há o relato de um caso em que a culpabilidade recaiu sobre um dos filhos do senhor. No ritual de adivinhação, foi indicado que o objeto furtado estava dentro de uma caixa, achada a referida caixa, foi localizado dentro dela os objetos roubados (ANTT, Inquisição de Lisboa, livro 784, pp. 113-114).
} 
PAIVA, José Pedro (1998). Bruxaria e superstição num país sem "caça às bruxas": 1600/1774. Lisboa. Notícias Editorial, 1997.

REIS, João J.; SILVA, Eduardo (1989). Negociação e conflito: a resistência negra no Brasil escravista. São Paulo: Companhia das Letras.

SLENES, Robert (1991-92). Malungu ngoma vem! África coberta e descoberta no Brasil. Revista da USP, São Paulo, n. 12, p. 12-67.

SLENES, Robert (1991-92). Malungu ngoma vem! África coberta e descoberta no Brasil. Revista da USP, São Paulo, n. 12, p. 12-67.

SWEET, James H. (2003). Recreating Africa: culture, Kinship, and religion in the Africa-Portuguese world, 1441-1770. London: The University of North Caroline Press, 2003.

\section{Autora}

\section{Glícia Caldas}

Mestranda em História Comparada pelo Instituto de Filosofia e Ciências Sociais da Universidade Federal do Rio de Janeiro. Orientador Prof. Dr. Francisco Weffort. Especialista em História da África pela Universidade Candido Mendes, Psicóloga pela Universidade Gama Filho, Bacharel em Direito pela Sociedade Universitária Augusto da Motta, Rio de Janeiro. É pesquisadora em assuntos afro-brasileiros da Assessoria de assuntos afrobrasileiros da Secretaria de Cultura do Estado do Rio de Janeiro, Professora de Ensino médio da rede pública estadual e Coordenadora Federal de Diversidade e Inclusão Educacional em Formação continuada em educação e relações étnico-raciais no Rio de Janeiro.

Fone (21) 3451-6902 Cel. 9281-4603

Rua Honório de Almeida, 68 - Irajá - RJ -21235-490

gliciarte@hotmail.com - medmag@click21.com.br

\section{Como citar este artigo:}

CALDAS, Glícia. A magia do feitiço: apropriações africanas no Brasil Colônia. Revista ACOALFAplp: Acolhendo a Alfabetização nos Países de Língua portuguesa, São Paulo, ano 1, n. 1, 2006. Disponível em: <http://www.acoalfaplp.net>. Publicado em: setembro de 2006. 